\title{
ANALISIS NILAI TAMBAH MELINJO PADA SENTRA INDUSTRI EMPING DI DESA BANDAR KECAMATAN SUKOMORO KABUPATEN MAGETAN
}

\author{
Eka Adityaningrum ${ }^{1}$, Sri Marwanti ${ }^{2}$, Wiwit Rahayu ${ }^{3}$ \\ ${ }^{1}$ Alumni Program Studi Agribisnis Fakultas Pertanian Universitas Sebelas Maret Surakarta \\ ${ }^{2,3}$ Dosen Program Studi Agribisnis Fakultas Pertanian Universitas Sebelas Maret Surakarta \\ email korespondensi: ekadityaningrum@gmail.com
}

\begin{abstract}
ABSTRACK
Agricultural commodities are generally produced as raw materials and are easily damaged, so they need to be directly consumed or processed first. The processing can increase the added value of agricultural products. The purpose of this study was to determine the cost, revenue, profit, efficiency, and value added of melinjo chips industry in Industrial Center at Bandar Village Sukomoro District Magetan Regency. The basic method of research used is descriptive analytical method. The determination of the sample area is purpossive which is Bandar Village Sukomoro District Magetan Regency because those village is the center of the melinjo chips industry in Magetan Regency. The respondents are found and gathered by using the proportional method and the respondents are found gathered simple random sampling method. The result of this research shows that total average cost spent by those industrialists in Bandar village is Rp5.816.109,00 per month. The average revenue for each of them is Rp7.826.667,00 per month and the profit is Rp2.010.492,00 per month. The running of melinjo chips industries is efficient. It can be known by efficiency value (R/C ratio) 1,42. The business of melinjo chips in Bandar Village, Sukomoro District, Magetan Regency provides added value of Rp. 8,645.00 / kg.
\end{abstract}

Keyword: Eficiency, Melinjo Chips, Value Added

\section{INTISARI}

Komoditas pertanian pada umumnya dihasilkan sebagai bahan mentah dan mudah rusak, sehingga perlu langsung dikonsumsi atau diolah terlebih dahulu. Proses pengolahan dapat meningkatkan nilai tambah dari produk pertanian. Tujuan dari penelitian ini adalah untuk mengetahui besarnya biaya, penerimaan, keuntungan, efisiensi, dan nilai tambah dari usaha emping melinjo di Desa Bandar Kecamatan Sukomoro Kabupaten Magetan. Metode dasar penelitian yang digunakan adalah metode deskriptif analitis. Penentuan daerah sampel dilakukan secara purposive yaitu Desa Bandar, Kecamatan Sukomoro Kabupaten Magetan karena desa tersebut merupakan sentra industri emping melinjo di Kabupaten Magetan. Pengambilan jumlah sampel responden tiap dusun dilakukan dengan cara proporsional dan pengambilan sampel responden masing-masing dusun dilakukan secara simple random sampling. Hasil penelitian ini menunjukkan bahwa rata-rata biaya total yang dikeluarkan oleh produsen emping melinjo di Desa Bandar selama satu bulan sebesar Rp5.816.109,00. Rata-rata penerimaan yang diperoleh setiap produsen adalah Rp7.826.667,00 per bulan dan rata-rata keuntungan yang diperoleh sebesar Rp2.010.492,00 per bulan. Usaha rumah tangga emping melinjo yang dijalankan selama ini sudah efisien yang ditunjukkan dengan $\mathrm{R} / \mathrm{C}$ rasio lebih dari 1 yaitu sebesar 1,42. Usaha emping melinjo Desa Bandar Kecamatan Sukomoro Kabupaten Magetan memberikan nilai tambah sebesar Rp8.645,00/kg.

Kata kunci: Efisiensi, Emping Melinjo, Nilai Tambah 
ISSN : 2622-6154 (print)

\section{PENDAHULUAN}

Agroindustri mempunyai peranan penting karena mampu menghasilkan nilai tambah dari produk segar hasil pertanian. Agroindustri di perdesaan yang berskala usaha kecil dan menengah serta industri rumah tangga, memiliki potensi, kedudukan, dan peranan yang cukup strategis untuk mewujudkan struktur perekonomian yang mampu memberikan pelayanan ekonomi, melaksanakan pemerataan, dan dapat mendorong pertumbuhan ekonomi serta mewujudkan stabilitas ekonomi. Hal ini berdasarkan pada saat keadaan krisis yang berkepanjangan, usaha kecil tetap mampu bertahan. Pengembangan dan pembinaan yang berkesinambungan diperlukan guna meningkatkan kemajuan pada industri tersebut agar mampu mandiri menjadi usaha yang tangguh dan juga memiliki keunggulan di dalam memberikan kepuasan konsumen serta dapat menciptakan peluang pasar yang lebih besar (Khoiriyah, et al, 2012).

Industri pengolahan hasil pertanian merupakan salah satu usaha yang dapat meningkatkan nilai tambah, meningkatkan kualitas hasil, meningkatkan penyerapan tenaga kerja, meningkatkan keterampilan produsen, dan meningkatkan pendapatan produsen. Pengembangan industri pengolahan hasil pertanian di Indonesia didukung dengan adanya sumberdaya alam pertanian yang mampu menghasilkan berbagai produk olahan yang dapat dikembangkan dengan sumberdaya alam lokal atau daerah yang ada. Berbagai wilayah di Indonesia memiliki kontribusi besar dalam memenuhi permintaan konsumen atau sebagai bahan baku industri rumah tangga.

Emping melinjo merupakan salah satu produk olahan dari hasil pertanian. Makanan ini adalah sejenis keripik yang dibuat dari buah melinjo yang sudah tua. Emping melinjo digemari oleh banyak orang karena rasanya yang gurih dan nikmat, serta disajikan di acara-acara besar seperti pernikahaan dan acara-acara keagamaan (Royfandi \& Amri, 2019). Adapun penelitian yang yang meneliti tentang emping melinjo yaitu (Aliudin dan \& Anggraeni, 2012) menyatakan bahwa Emping melinjo merupakan salah satu bahan makanan ringan, selain bernilai gizi tinggi juga memiliki cita rasa yang banyak disukai masyarakat. Emping melinjo merupakan makanan istimewa dalam pola makanan rakyat Indonesia.

Kabupaten Magetan adalah salah satu daerah yang memiliki unit usaha emping melinjo yang sampai sekarang masih aktif berproduksi. Jumlah unit usaha emping melinjo di Kabupaten Magetan adalah sebanyak 218 unit dengan 402 tenaga kerja yang tersebera di 2 kecamatan yaitu Kecamatan Magetan dan Kecamatan Sukomoro. Kecamatan Sukomoro adalah penghasil emping melinjo terbanyak di Kabupaten Magetan. Salah satu daerah di Kecamatan Sukomoro yang memiliki jumlah unit usaha emping melinjo paling banyak adalah Desa Bandar dengan 94 unit usaha emping melinjo. Desa Bandar juga merupakan sentra industri emping melinjo di Kabupaten Magetan. Adanya industri yang mengubah melinjo menjadi emping melinjo akan dapat memberikan nilai tambah karena dikeluarkan biaya-biaya sehingga terbentuk harga baru yang lebih tinggi dan keuntungan yang lebih besar bila dibandingkan tanpa melalui proses pengolahan. Nilai tambah merupakan penambahan nilai suatu komoditi akibat adanya perlakuan tertentu 
terhadap komoditi tersebut. Nilai tambah menjadi sangat penting dalam meningkatkan pendapatan masyarakat.

\section{METODE PENELITIAN}

Metode penelitian yang digunakan adalah metode analisis deskriptif. Penelitian ini dilakukan di Kabupaten Magetan. Penentuan daerah sampel dilakukan secara sengaja (purposive). Penentuan sampel dalam penelitian ini menggunakan teknik sensus. Penelitian ini menggunakan data sekunder dan primer dengan teknik pengumpulan data yaitu dengan cara dokumentasi, wawancara, dan pencatatan. Penelitian dilakukan pada bulan Desember 2018.

\section{Analisis Biaya, Penerimaan, dan Keuntungan}

Berikut ini merupakan perhitungan analisis biaya, penerimaan, dan keuntungan (Soekartawi, 1995):

$\mathrm{TC}=\mathrm{TFC}+\mathrm{TVC}$

dimana :

TC = biaya total usaha emping melinjo (Rupiah)

TFC = total biaya tetap usaha emping melinjo (Rupiah)

TVC = total biaya variabel usaha emping melinjo (Rupiah)

Penerimaan secara matematis dirumuskan sebagai berikut :

$\mathrm{TR}=\mathrm{Q} \times \mathrm{P}$

dimana

$\mathrm{TR}=$ penerimaan total usaha emping melinjo (Rupiah)

$\mathrm{Q}=$ jumlah emping melinjo yang dihasilkan (bungkus)

$\mathrm{P}=$ harga emping melinjo per unit (Rupiah) berikut :

Metode perhitungan keuntungan secara matematis dirumuskan sebagai

$\pi=\mathrm{Q} \times \mathrm{P}-(\mathrm{TFC}+\mathrm{TVC})$

$\pi \quad=$ keuntungan usaha emping melinjo (Rupiah)

$\mathrm{Q} \quad=$ jumlah emping melinjo yang terjual $(\mathrm{kg})$

$\mathrm{P} \quad=$ harga emping melinjo per $\mathrm{kg}$ (Rupiah)

TFC = total biaya tetap usaha emping melinjo (Rupiah)

TVC = total biaya variabel usaha emping melinjo (Rupiah)

\section{Efisiensi Usaha}

Efisiensi usaha dapat diketahui dengan menggunakan perhitungan R/C rasio. R/C rasio adalah singkatan dari Return Cost. Secara matematis dapat dirumuskan sebagai berikut (Soekartawi, 1995) :

Efisiensi $=\frac{R}{C}$

keterangan :

$\mathrm{R}=$ penerimaan usaha emping melinjo (Rupiah)

$\mathrm{C}=$ biaya yang dikeluarkan dari usaha emping melinjo (Rupiah)

Kriteria yang digunakan dalam penilaian efisiensi usaha adalah :

$\mathrm{R} / \mathrm{C}>1$ berarti usaha emping melinjo yang dijalankan efisien. 
$\mathrm{R} / \mathrm{C}=1$ berarti usaha emping melinjo belum efisien atau usaha mencapai titik impas.Nilai Tambah

Nilai tambah yang dihitung adalah nilai tambah dengan menggunakan metode Hayami. Perhitungan nilai tambah menurut metode Hayami dapat dilihat pada Tabel 1.

Tabel 1. Perhitungan Nilai Tambah Menurut Metode Hayami

\begin{tabular}{lll}
\hline \hline No & \multicolumn{1}{c}{ Variabel } & \multicolumn{1}{c}{ Nilai } \\
\hline 1. & Emping melinjo yang dihasilkan (kg/produksi) & $\mathrm{A}$ \\
2. & Jagung yang digunakan(Kg/produksi) & $\mathrm{B}$ \\
3. & Tenaga Kerja (jam/produksi) & $\mathrm{C}$ \\
4. & Faktor Konversi (1/2) & $\mathrm{D}=\mathrm{a} / \mathrm{b}$ \\
5. & Koefisien Tenaga Kerja (3/2) & $\mathrm{E}=\mathrm{c} / \mathrm{b}$ \\
6. & Harga Emping melinjo (Rp/kg) & $\mathrm{F}$ \\
7. & Upah rata-rata tenaga kerja (Rp/jam) & $\mathrm{G}$ \\
8. & Harga Jagung(Rp/kg) & $\mathrm{H}$ \\
9. & Sumbangan Input Lain (Rp/kg output) & $\mathrm{I}$ \\
10. Nilai Output Emping melinjo (4x6) (Rp) & $\mathrm{J}=\mathrm{dxf}$ \\
11. & a. Nilai Tambah (10-9-8) (Rp) & $\mathrm{K}=\mathrm{j}-\mathrm{h}-\mathrm{i}$ \\
& b. Rasio Nilai Tambah (11a/10)x100\% & $\mathrm{I}(\%)=(\mathrm{k} . \mathrm{j}) \times 100 \%$ \\
12. & a. Imbalan tenaga kerja (5x7) (Rp) & $\mathrm{M}=\mathrm{exg}$ \\
& b. Bagian tenaga kerja (12a/11a)x100\% & $\mathrm{n}(\%)=(\mathrm{mxk}) \times 100 \%$ \\
13. & a. Keuntungan (11a-12a) (Rp) & $\mathrm{O}=\mathrm{k}-\mathrm{m}$ \\
& b. Tingkat Keuntungan $(13 \mathrm{a} / 11 \mathrm{a}) \times 100 \%$ & $\mathrm{P}(\%)=(\mathrm{o} / \mathrm{k}) \times 100 \%$ \\
\hline \hline
\end{tabular}

Sumber: Hayami et al, 1987

\section{HASIL DAN PEMBAHASAN}

Nilai tambah melinjo pada sentra industri emping adalah penerimaan yang diperoleh dikurangi dengan biaya bahan baku yang digunakan dan biaya input lainnya (Aliudin \& Dian Anggraeni, 2012). Adapun hasil dari analisis yang telah dilakukan pada penelitian ini ialah sebagai berikut.

\section{Karakteristik Usaha Emping Melinjo di Desa Bandar Kecamatan Sukomoro Kabupaten Magetan}

Metode analisis yang digunakan dalam penelitian ini adalah analisis analisis deskriptif. Usaha emping melinjo di Desa Bandar sudah diusahakan sejak belasan bahkan puluhan tahun yang lalu. Usaha emping melinjo di Desa Bandar dijalankan dengan berbagai alasan yaitu sebagai warisan usaha, karena tidak memiliki pekerjaan lain ataupun karena pengalaman sebagai buruh. Usaha Usaha emping melinjo di Desa Bandar merupakan usaha utama ataupun usaha sampingan dari para produsen emping melinjo. Penggunaan tenaga kerja dalam keluarga mendominasi curahan kerja pada masing-masing unit usaha. Rata-rata harga biji melinjo berkisar Rp10.000,00-Rp12.000,00 per kilogram. Pemasaran produk emping melinjo sebagian besar dijual ke pedagang pengumpul dari dalam ataupun luar kota. Pemasaran emping melinjo juga dilakukan dengan perantara sales. Rata-rata harga jual emping melinjo adalah 
sebesar Rp 45.000,00 per kilogram.

\section{Analisis Usaha Emping Melinjo di Desa Bandar Kecamatan Sukomoro} Kabupaten Magetan

Faktor yang mempengaruhi keuntungan usaha emping melinjo adalah penerimaan (TR) dan biaya usaha emping melinjo (TC). Penerimaan pada usaha emping melinjo merupakan nilai produksi yang diperoleh dari perkalian antara jumlah produksi emping melinjo yang dihasilkan dengan harga produksi emping melinjo yang dihasilkan, sedangkan biaya usaha emping melinjo meliputi biaya tetap (penyusutan alat dam biaya bunga modal) dan biaya variabel (biaya pembelian biji melinjo, pasir, arang, pengemasan, transportasi, dan tenaga kerja).

Tabel 2. Rata-rata Penerimaan, Biaya, Keuntungan. dan Efisiensi Usaha Emping Melinjo di Desa Bandar Kecamatan Sukomoro Kabupaten Magetan

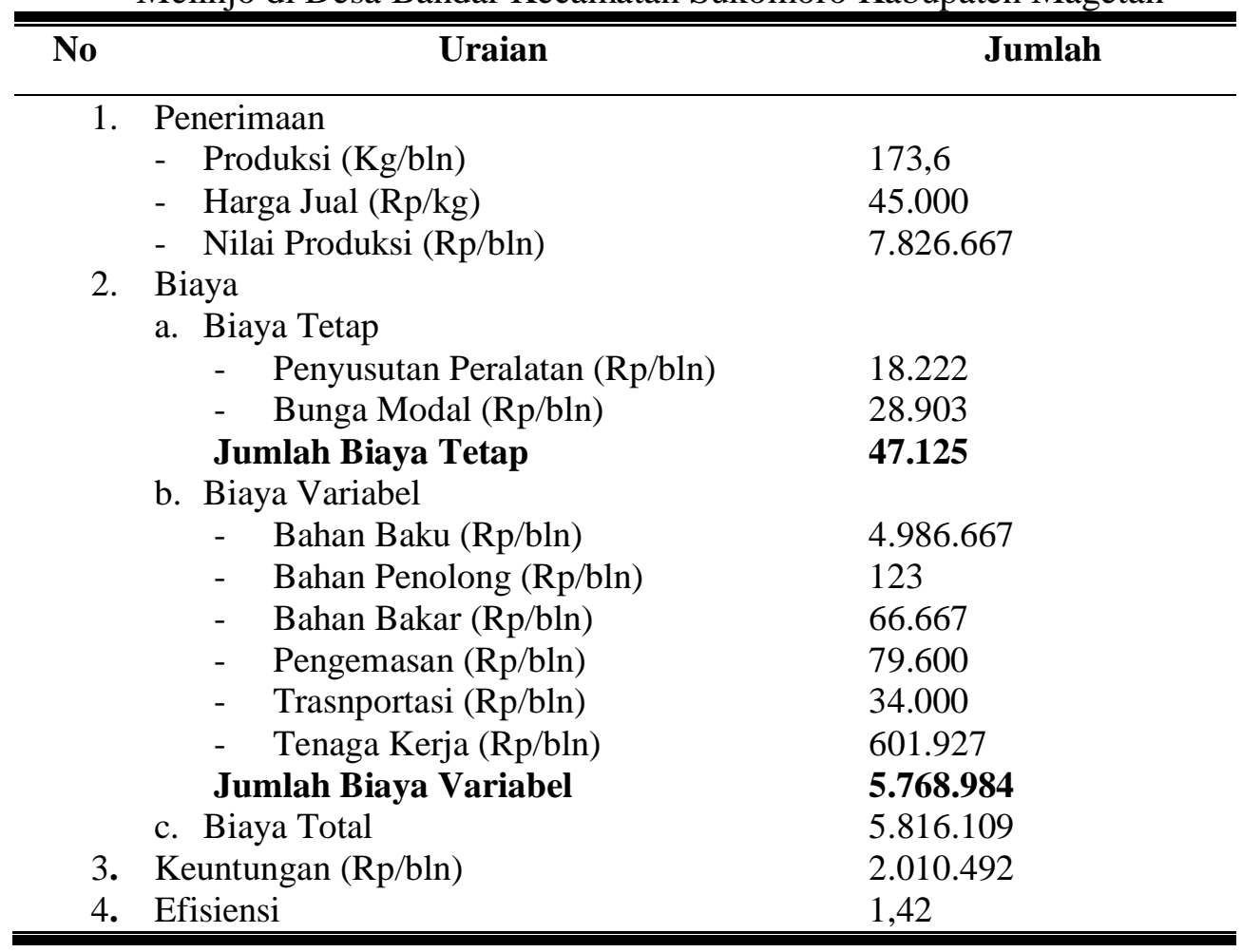

Sumber : Analisi Data Primer

Tabel 2 menunjukkan bahwa rata-rata biaya tetap yang dikeluarkan produsen emping melinjo di Desa Bandar Kecamatan Sukomoro Kabupaten Magetan adalah sebesar Rp 47.125. Sumber biaya tetap terbesar berasal dari biaya bunga modal sebesar Rp 28.903. Nilai suku bunga diperoleh dari data Bank BRI yaitu sebesar 1,45\% pada bulan Desember 2018 sebab penelitian ini dilakukan pada bulan tersebut. Biaya penyusutan peralatan yaitu sebesar Rp18.222.

Rata-rata biaya variabel yang dikeluarkan oleh produsen emping melinjo di Desa Bandar Kecamatan Sukomoro Kabupaten selama satu bulan adalah sebesar 
Rp5.768.984,00. Biaya variabel terbesar dari usaha emping melinjo adalah biaya bahan baku berupa biji melinjo sebesar Rp4.986.66700. Rata rata penggunaan bahan baku selama satu bulan sebanyak $455 \mathrm{~kg}$ dengan harga ratarata Rp 12.000 per kg. Biaya variabel terbesar kedua adalah biaya bahan penolong yakni sebesar Rp123,00 Bahan penolong adalah bahan yang digunakan sebagai tambahan atau pelengkap dalam proses produksi untuk menghasilkan emping melinjo. Biaya pengemasan yang dikeluarkan oleh produsen emping melinjo di Kabupaten Magelang selama satu bulan rata-rata sebesar Rp79.600.

Rata-rata biaya total yang dikeluarkan oleh produsen emping melinjo di Desa Bandar Kecamatan Sukomoro Kabupaten selama satu bulan adalah sebesar

Rp 5.816.175,00. Biaya adalah nilai korbanan yang dikeluarkan dalam proses produksi. Biaya dalam penelitian ini adalah seluruh biaya yang dikeluarkan untuk proses pembuatan emping meinjo di Kabupaten Pidie Kecamatan Mutiara, baik biaya yang benar-benar dikeluarkan atau tidak benar- benar dikeluarkan. Biaya tersebut terdiri dari biaya tetap dan biaya variabel (Royfandi \& Amri, 2019). Biaya terbesar yang dikeluarkan oleh produsen emping melinjo adalah biaya variabel sebesar Rp5.786. Hal ini disebabkan komposisi biaya variabel lebih banyak daripada biaya tetap dan biaya variabel menyesuaikan dengan produksi emping melinjo dan tingginya harga dari bahan-bahan seperti bahan baku, bahan penolong, pengemasan, tenaga kerja dan bahan bakar.

Penerimaan produsen emping melinjo di Desa Bandar Kecamatan Sukomoro Kabupaten adalah sebesar Rp7.826.667,00. Emping melinjo yang terjual oleh produsen selama satu bulan rata-rata sebesar $173,6 \mathrm{~kg}$ dengan ratarata harga tiap $\mathrm{kg}$ emping melinjo $\mathrm{Rp} 45.000,00$. Keuntungan rata-rata yang

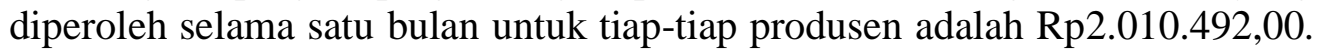
Produksi emping melinjo tetap dilakukan oleh para produsen walaupun keuntungan yang didapatkan tidak besar. Hal ini disebabkan karena pada kondisi nyata banyak biaya yang tidak riil dikeluarkan oleh produsen, seperti bunga modal investasi dan upah tenaga kerja keluarga.

Efisiensi usaha emping melinjo skala rumah tangga di Desa Bandar Kecamatan Sukomoro Kabupaten sebesar 1,42. Hal ini berarti bahwa usaha emping melinjo yang telah dijalankan sudah efisien yang ditunjukkan dengan nilai $\mathrm{R} / \mathrm{C}$ rasio lebih dari satu. $\mathrm{R} / \mathrm{C}$ rasio ini menunjukkan pendapatan kotor yang diterima untuk setiap rupiah yang dikeluarkan untuk memproduksi. Nilai $\mathrm{R} / \mathrm{C}$ rasio 1,42 berarti bahwa setiap $\mathrm{Rp} 1,00$ biaya yang dikeluarkan produsen emping melinjo memberikan penerimaan sebesar $\mathrm{Rp} 1,42$. 


\section{Analisis Nilai Tambah Usaha Emping Melinjo di Desa Bandar Kecamatan Sukomoro Kabupaten Magetan}

Tabel 3. Rata-rata Nilai Tambah Usaha Emping Melinjo di Desa Bandar Kecamatan Sukomoro Kabupaten Magetan Pada Bulan Desember 2018

\begin{tabular}{clr}
\hline \hline No & \multicolumn{1}{c}{ Uraian } & Nilai \\
\hline 1. & Hasil Produksi (kg/produksi) $(1)$ & 6,73 \\
2. & Bahan Baku (kg/produksi) (2) & 13,47 \\
3. & Input Tenaga Kerja (JKO/produksi) $(3)$ & 4,61 \\
4. & Faktor Konversi (1)/(2) & 0,50 \\
5. & Koefisien Tenaga Kerja (3)/(2) & 0,46 \\
6. & Harga Produk (Rp/kg) $(6)$ & $45.000,00$ \\
7. & Upah Rata-rata Tenaga Kerja $(\mathrm{Rp} / \mathrm{JKO})(7)$ & $2.143,00$ \\
8. & Harga Bahan Baku (Rp/kg) $(8)$ & $11.567,00$ \\
9. & Sumbangan Input Lain $(\mathrm{Rp} / \mathrm{kg})(9)$ & $2.163,00$ \\
10. & Nilai Akhir Output $(\mathrm{Rp} / \mathrm{kg})(4) \times(6)$ & $22.375,00$ \\
11. & Nilai Tambah $(\mathrm{Rp} / \mathrm{kg})(10)-(8)-(9)$ & $8.645,00$ \\
12. & Rasio Nilai Tambah $(\%)(11) /(10) \times 100 \%$ & 38,61 \\
13. & Imbalan Tenaga Kerja $(\mathrm{Rp} / \mathrm{kg})(5) \times(7)$ & 846,00 \\
14. & Bagian Tenaga Kerja $(\%)(13) /(11) \times 100 \%$ & 9,96 \\
15. & Keuntungan $(\mathrm{Rp} / \mathrm{kg})(11-13)$ & $7.799,00$ \\
16. & Tingkat Keuntungan $(15 / 11) \times 100 \%$ & 90,04 \\
\hline \hline
\end{tabular}

Sumber: Analisis Data Primer

Dari hasil perhitungan nilai tambah pada Tabel 3 diketahui bahwa ratarata hasil produksi (output) industri emping melinjo di Desa Bandar Kecamatan Sukomoro Kabupaten Magetan adalah sebesar 6,73 kg untuk satu kali produksi. Dalam satu kali produksi penggunaan bahan baku (input) biji melinjo rata-rata sebesar 13,47 kg. Harga jual emping melinjo dalam $1 \mathrm{~kg}$ sebesar Rp45.000,00. Input lain atau bahan penolong yang digunakan dalam satu kali proses produksi emping melinjo sebesar Rp2.163,00 terdiri dari $1 \mathrm{~kg}$ pasir dengan harga $\mathrm{Rp} 23 / \mathrm{kg}$ dan arang $1 \mathrm{~kg}$ dengan harga $\mathrm{Rp} 2.140 / \mathrm{kg}$. Proses produksi emping melinjo rata-rata menggunakan 1 orang tenaga kerja dengan waktu yang digunakan sebanyak 4,61 $\mathrm{JKO}$ /produksi. Berdasarkan hasil pembagian total output per input bahan baku utama didapatkan nilai faktor konversi sebesar 0,50. Nilai ini menunjukan bahwa setiap 1 $\mathrm{kg}$ biji melinjo yang diolah akan menghasilkan emping melinjo sebesar 0,50 kg. Hal ini dikarenakan dalam pengolahan biji melinjo menjadi emping melinjo mengalami penyusutan kadar air karena proses penyangraian dan juga penjemuran.

Nilai koefisien tenaga kerja diperoleh dari hasil pembagian antara jumlah jam kerja (JKO) dengan jumlah input bahan baku yang diolah. Hasil perhitungan tersebut menunjukan bahwa nilai koefisien tenaga kerja pada usaha industri emping melinjo sebesar 0,46 JKO/kg. Nilai output emping melinjo diperoleh dari hasil perkalian harga produk per $\mathrm{kg}$ dengan faktor konversi. Harga rata-rata emping melinjo adalah Rp45.000,00 per kg dan faktor konversi sebesar 0,50, sehingga didapat nilai output emping melinjo yang dihasilkan yaitu sebesar Rp22.375,00. Nilai sumbangan input lain diperoleh dengan pembagian antara jumlah bahan penolong dan bahan bakar 
yang digunakan dalam satu kali produksi dengan jumlah output emping melinjo yang dihasilkan sebanyak $6,73 \mathrm{~kg}$ sehingga diperoleh sumbangan input lain sebesar Rp2.163/kg. Untuk rata-rata harga bahan baku yaitu sebesar Rp11.567,00/kg. Berdasarkan nilai output maka dapat diketahui nilai tambah sebesar Rp8.645,00 dengan rasio nilai tambah $38,61 \%$. Nilai ini dapat diinterpretasikan bahwa $38,61 \%$ dari nilai output merupakan nilai tambah pengolahan biji melinjo klathak menjadi emping melinjo.

Tenaga kerja yang dihitung adalah semua tenaga kerja yang berperan langsung dalam proses pengolahan melinjo. Pada pengolahan produk ini, umumnya diperlukan 3- 4 orang tenaga kerja luar untuk proses produksi dengan waktu kerja 8-10 jam/hari (Yoesti \& Lestari, 2019). Imbalan tenaga kerja merupakan perkalian dari koefisien tenaga kerja dengan upah rata - rata tenaga kerja per JKO. Tingkat upah tenaga kerja adalah sebesar Rp2.143,00 per JKO. Pada perhitungan nilai tambah di atas, imbalan tenaga kerja yang diberikan dari setiap $1 \mathrm{~kg}$ bahan baku biji melinjo klathak yang diolah menjadi emping melinjo adalah Rp846,00 dengan demikian bagian tenaga kerja dalam pengolahan emping melinjo ini adalah sebesar 9,96\%. Keuntungan usaha emping melinjo skala rumah tangga di Desa Bandar merupakan selisih antara nilai tambah dengan imbalan tenaga kerja, sehingga dianggap sebagai nilai tambah bersih yang diterima oleh produsen emping melinjo. Nilai tambah yang diperoleh dari pengolahan biji melinjo klathak menjadi emping melinjo sebesar Rp8.645,00 dan imbalan tenaga kerja sebesar Rp846,00 sehingga keuntungan yang didapat dari usaha emping melinjo skala rumah tangga di Desa Bandar sebesar Rp7.799,00 dengan tingkat keuntungan $90,04 \%$ dan output yang dihasilkan sebesar $6,73 \mathrm{~kg} / \mathrm{produksi}$ dengan input yang digunakan sebesar $13,47 \mathrm{~kg} /$ produksi.

\section{KESIMPULAN}

Berdasarkan hasil penelitian dan analisis yang telah dilakukan, maka dapat diperoleh kesimpulan yaitu, rata-rata keuntungan yang diperoleh produsen emping melinjo di Desa Bandar adalah sebesar Rp2.010.492,00 per bulan. Usaha emping melinjo di di Desa Bandar Kecamatan Sukomoro Kabupaten Magetan sudah efisien dengan nilai efisiensi lebih dari satu yaitu sebesar 1,42. Usaha emping melinjo di Desa Bandar Kecamatan Sukomoro Kabupaten Magetan memberikan nilai tambah sebesar Rp8.645,00/kg atau rasio nilai tambah sebesar 38,61\%. 
ISSN : 2622-6154 (print)

\section{DAFTAR PUSTAKA}

Aliudin dan Dian Anggraeni. (2012). NILAI TAMBAH EMPING MELINJO MELALUI TEKNOLOGI PRODUKSI KONVENSIONAL DI DESA MENES KECAMATAN MENES KABUPATEN PANDEGLANG. AGRIKA, 6(1), 1-12.

Badan Penelitian dan Pengembangan 2016. http://balitsereal.litbang.pertanian.go.id/wpcontent/uploads/2016/11/duatiga. pd. Diakses 24 April 2018.

Badan Penelitian dan Pengembangan. 2011. Prospek dan Arah Pengembangan Agribisnis: Dukungan Aspek Teknologi Pascapanen. http://www.litbang.deptan.go.id/special/komoditas/blpascapanen. Diakses 19 Oktober 2011.

Badan Pusat Statistik. 2011. Profil Industri Mikro dan Kecil. Badan Pusat Statistik. Jakarta.

Darmawan, T., dan Masroh, A.H., 2004. Pentingnya Nilai Tambah Produk Pangan

Dinas Perindustrian dan Perdagangan. 2016. Usaha Industri Makanan Olahan. Magetan.

Hayami Y, Yhosinori M, dan Masdjikin S. 1987. Agricultural Marketing and Processing in Upland Java: A Ptospectif From A Sunda Village. Bogor: ESCAP CGPRT Centre.

Khoiriyah, N. R., Ariyani, A. H., \& Fauziyah, E. (2012). Strategi Pengembangan Agroindustri Kerupuk Terasi. Jurnal Agriekonomika, 1(2), 135-148. https://doi.org/http://dx.doi.org/10.21107/agriekonomika.v1i2.357

Royfandi, M. Y., \& Amri. (2019). ANALISA USAHA DAN PEMASARAN EMPING MELINJO DI KECAMATAN MUTIARA KABUPATEN PIDIE M.Yogi. Jurnal Ilmiah Mahasiswa (JIM), 4(2), 48-58.

Singarimbun, M. dan Efendi. 2001. Metode Penelitian Survey. LP3S. Jakarta. Soekartawi. 1996. Agroindustri. Raja Grafindo. Jakarta.. 2002. Analisis Usaha Tani. UI- Press. Jakarta.

Yoesti Silvana Arianti1, L. R. W. (2019). Analisis Nilai Tambah dan Strategi Pengembangan Agroindustri Gula Merah di Kabupaten Madiun. Jurnal Ekonomi Pertanian Dan Agribisnis, 3(2), 256-266. https://doi.org/10.21776/ub.jepa.2019.003.02.4 